\title{
Seroprevalencia de rinotraqueitis infecciosa bovina en hatos lecheros de Toca - Boyacá
}

\section{Seroprevalence of infectious bovine rhinotracheitis in dairy herds Toca - Boyaca}

\author{
Ximena Ochoa, ${ }^{1}$ MVZ, Marcela Orbegozo, ${ }^{1}$ MVZ, Fred Manrique-Abril, ${ }^{2 *}$ Ph.D, \\ Martín Pulido M, ${ }^{1,3}$ MVZ, Juan Ospina, ${ }^{4}$ M.Sc.
}

\begin{abstract}
${ }^{1}$ Universidad Pedagógica y Tecnológica de Colombia Tunja. Grupo GIDIMEVETZ. Facultad de Ciencias Agropecuarias UPTC. Tunja, Boyacá, Colombia. ${ }^{2}$ Universidad Nacional de Colombia. Director Grupo de investigación en Salud Pública GISP-UPTC. 'Universidad Pedagógica y Tecnológica de Colombia. Antiguo Hospital San Rafael. Tunja, Boyacá, Colombia. ${ }^{4}$ Universidad Pedagógica y Tecnológica de Colombia, Investigador Grupo de investigación en Salud Publica GISP-UPTC. Escuela de Medicina Antiguo Hospital San Rafael. Tunja, Boyacá, Colombia. *Correspondencia: gisp@uptc.edu.co
\end{abstract}

Recibido: Febrero de 2010; Aceptado: Abril 2011.

\section{RESÚMEN}

Objetivo. Determinar la Seroprevalencia de rinotraqueitis infecciosa bovina (IBR) en hatos lecheros del municipio de Toca - Boyacá. Materiales y métodos. Se recolectaron 80 muestras de sangre de hembras bovinas que estuvieran en producción, o que dentro de su historial reportaran un parto, especificando datos de cada una, identificación, edad, número de partos, problemas reproductivos que presentaban y el tipo de alteración reproductiva. Las muestras de suero fueron procesadas para determinar la presencia de anticuerpos de la enfermedad. Resultados. La seroprevalencia para IBR, en el municipio de Toca - Boyacá, fue de $35.65 \%$, distribuida así: $17.9 \%$ en ejemplares entre 24-60 meses, $60.7 \%$ en animales de entre $72-108$ meses y $21.4 \%$ en animales mayores de 109 meses; la prueba fue positiva en $32 \%$ de las vacas con problemas reproductivos $(n=8)$, en $1.25 \%$ $(n=1)$ de la muestra se registró antecedente de aborto y prueba positiva. Conclusiones. El presente trabajo constituye el primer reporte de análisis de esta enfermedad en el municipio de Toca-Boyacá, que demuestra la presencia de la enfermedad en la zona. Simultáneamente, se plantea que esta afección pueda ser uno de los posibles factores de riesgo que afecta la rentabilidad económica de las producciones lecheras.

Palabras clave: Análisis de sangre, anticuerpos, bovinos, seroprevalencia, suero (Fuente: CAB).

\begin{abstract}
Objective. Determining the Seroprevalence of infectious bovine rhinotracheitis (IBR) in dairy herds in the municipality of Toca - Boyaca. Materials and methods. 80 blood samples were collected from female cattle that were in production or, that had a delivery reported in their charts, specifying data on each one of them: identification, age, number of deliveries, reproductive problems they presented as well as the types of reproductive impairments present. Serum samples were processed to determine the presence of antibodies of the disease. Results. The seroprevalence of IBR in the
\end{abstract}


municipality of Toca - Boyaca, was of 35.65\%, distributed as follows: $17.9 \%$ in specimens between 24-60 months, $60.7 \%$ in animals of $72-108$ months and $21.4 \%$ in animals older than 109 months; the test was positive in $32 \%$ of cows with reproductive problems $(n=8)$, a history of abortion and positive test was reported in $1.25 \%(n=1)$ of the sample. Conclusions. This work constitutes the first report of analysis of this disease in the municipality of Toca-Boyacá, demonstrating the presence of disease in the area. Concurrently, it suggests that this condition may be one of the possible risk factors affecting the economic profitability of dairy production.

Key words: Antibodies, blood analysis, bovine, seroprevalence, serum (Source: CAB).

\section{INTRODUCCIÓN}

La Rinotraqueitis Infecciosa Bovina (IBR) puede adoptar diversas formas que incluyen la afectación respiratoria asociada a abortos endémicos, la forma conjuntival, la forma genital que afecta el tracto reproductor y la forma septicémica de los neonatos que se caracteriza básicamente por encefalitis (1).

Blood en 1973 reporta que, la IBR se describió primero como una enfermedad del tracto respiratorio en ganado de engorde en Western EEUU en 1955, aislándose el virus en 1956, actualmente se ha visto que la enfermedad tiene una distribución mundial (2-7).

Moraga (8), indica que las manifestaciones clínicas de la IBR han variado a través del tiempo y la gravedad de los animales enfermos cambia de un país a otro; esta dinámica en las enfermedades asociadas al IBR tipo 1, probablemente se deba a factores cambiantes en el manejo de los animales, patogenicidad incrementada de las diferentes cepas virales y asociación sinérgica con otros agentes infecciosos.

De otra parte en un estudio realizado en los departamentos de Córdoba y Sucre, durante los años 1980 - 1984, se encontró una prevalencia del $29.6 \%$ en muestras de suero provenientes de 2295 bovinos. El estudio demostró que no existieron diferencias significativas entre el ganado lechero y el de carne y que los índices de prevalencia aumentaron progresivamente conforme aumentó la edad de los animales (3).

En el año 1982 se reportó que en hembras de bovino analizadas en Colombia, hubo una seroprevalencia del $51.7 \%$ en la región Caribe, del $21.5 \%$ en la región Andina y de $20.6 \%$ para el piedemonte llanero (9). Por otro lado, Góngora y Villamil en 1995 reportaron que en toros de la sabana de Bogotá, un $15.3 \%$ de reactores positivos (10).

El objetivo de este estudio y teniendo en cuenta la alta prevalencia de esta enfermedad en algunas regiones de Colombia y los antecedentes históricos de la misma, se realizó un tamizaje mediante serología con el propósito de identificar anticuerpos contra Herpes virus Bovino tipo 1 en sueros extraídos de una muestra de hembras seleccionadas aleatoriamente, mediante la técnica de ELISA indirecta, con el fin de obtener información que reflejara la situación actual de prevalencia de la IBR, en el municipio de Toca - Boyacá, como punto de partida en la futura elaboración de proyectos que busquen la identificación de entidades patológicas que afecten la producción pecuaria en el departamento.

\section{MATERIALES Y MÉTODOS}

Sitio de estudio. El presente estudio se llevó a cabo en el municipio de Toca - Boyacá, área en la que confluyen una serie de características geográficas que permiten el desarrollo de múltiples labores agropecuarias. Limita por el norte, con Tuta; por el sur, con Siachoque; por el oriente, con Pesca y por el occidente, con Tuta y Chivatá, su extensión total es de 168 Km², tiene una altitud de 2810 msnm y su temperatura media es de $13^{\circ} \mathrm{C}(11)$.

Tipo de estudio y tamaño de la muestra. Previo diseño de protocolo se adelantó un estudio de tipo analítico descriptivo de corte transversal con muestreo aleatorio simple y distribución proporcional al tamaño del hato. Para el análisis estadístico se manejaron los programas EPI-INFO $2002 \&$ y EPIDAT $3.0 \&$ para datos tabulados.

En la interpretación de los datos estadísticos se consideró un nivel de significancia del 5\%. En el componente analítico, se utilizó la distribución Chi-cuadrado $\chi^{2}$ y análisis de contingencia para medir la fuerza de asociación entre las diferentes variables. En cuanto al análisis de variables cuantitativas se adelantó análisis de varianza, ANOVA de un factor estadístico y prueba $t$ con intervalo de confianza del $95 \%$. 
Selección de la muestra. Debido a factores y características particulares propias de cada una de las fincas, se limitaron algunos criterios de inclusión, no obstante, se seleccionaron mediante muestreo un total de 80 hembras mayores de 24 meses de raza Holstein, ubicadas en fincas del municipio de Toca - Boyacá, durante el mes de abril del 2008. Las muestras fueron tomadas e identificadas con un número según el orden secuencial que se llevaba en el registro del estudio. El tamaño de la muestra se calculó con base a la probabilidad de detectar diferencias significativas con $a=0.05$ y poder estadístico del $80 \%$ por cada mil animales, del $8.5 \%$, acorde con las prevalencias registradas en los reportes de estudios previos $(3,9)$; se estimó un tamaño de muestra de 78 animales.

Adicionalmente, de cada una de las fincas se capturaron datos acerca del tipo de explotación que se tenia y el manejo de los animales en general. Se muestrearon hembras que estuvieran en producción, o que por lo menos, dentro de su historial reportaran un parto, especificando datos de cada una, como identificación, edad, número de partos, problemas reproductivos que presentaban y el tipo de alteración en los procesos de producción.

Obtención del suero y procesamiento de la muestra. Una vez seleccionada la población y técnicas de muestreo, y asumiendo rigurosamente las correspondientes medidas de asepsia y bioseguridad, las muestras fueron recogidas e identificadas con un número según el orden secuencial que se llevaba en el registro. El sitio de punción seleccionado para la obtención de la muestra de sangre fue la vena caudal, lugar de donde se obtuvieron entre 3 a $5 \mathrm{ml}$ por muestra. El periodo máximo transcurrido entre la recolección y el envío al laboratorio no superó las 24 horas, las muestras se conservaron en refrigeración hasta ser llevadas al laboratorio de la clínica veterinaria de grandes y pequeños animales de la UPTC, localizada en la ciudad de Tunja, sitio en el cual se procedió a centrifugarlas para el correspondiente aislamiento de los sueros; cada una de las muestras se centrifugó a 3600 r.p.m. durante 5 minutos para la obtención del correspondiente suero.

El respectivo análisis serológico se adelantó en el laboratorio Medico Veterinario L.M.V LTDA, ubicado en la ciudad de Bogotá, donde se realizó, mediante el empleo del Kit comercial del laboratorio POURQUIER ®ELISA IBR-IPV, la determinación sobre la presencia o no de anticuerpos contra el Herpes virus Bovino tipo 1.
Según el laboratorio que produce el reactivo, los resultados se pueden considerar fiables en caso de que: El control positivo, tenga una mínima media OD.450 valor de: 0,350. De tal manera al obtener las DO de cada una de las muestras analizadas se hicieron cálculos mediante la utilización de la siguiente ecuación:

$$
S / P \%=(M X-C N / C P-C N)
$$

Donde $\mathrm{MX}=$ suero problema; $\mathrm{CP}=$ control positivo; $\mathrm{CN}=$ control negativo.

Con base en lo anterior, y de acuerdo con los registros del laboratorio, se consideró que los animales positivos a IBR tendrían $S / P \geq 55 \%$; animales sospechosos presentarían $\mathrm{S} / \mathrm{P}=45 \%$ $55 \%$ y animales negativos mostrarían $\mathrm{S} / \mathrm{P} \leq 45 \%$ $(1,12-14)$.

Para realizar las asociaciones entre el factor de riesgo y la enfermedad se utilizó la medida de asociación o de efecto OR (Odds Ratio), medida epidemiologica que determina los grados de asociación y se interpreta de la siguiente forma:

- $\mathrm{OR}=1$ indica que no hay asociación entre la presencia del factor de riesgo y el evento.

-EI OR>1 indica que existe asociación positiva, es decir, que la presencia del factor de riesgo se asocia a una mayor frecuencia de suceder el evento.

- El OR<1 indica que existe una asociación negativa, es decir, que no existe factor de riesgo, que lo que existe es un factor protector.

\section{RESULTADOS}

La seroprevalencia hallada para IBR en el municipio de Toca - Boyacá, fue, con la respectiva corrección para una sensibilidad del $96 \%$ y especificidad del $97 \%$, de $35.65 \%$ (Tabla 1) con un intervalo de confianza (95\%) de 24.7 a $46.5 \%$, lo que significa que de los 80 bovinos muestreados 28 vacas presentaron la enfermedad, con valores S/P que estuvieron entre 0.93 y 4.07 , dejando 52 hembras como negativas, con S/P entre 0 y 0.34 , y ningún animal sospechoso.

Tabla 1. Resultados de la seroprevalencia hallada para la Rinotraqueitis Infecciosa Bovina (IBR) en el municipio de Toca - Boyacá.

\begin{tabular}{lcc}
\hline \multicolumn{1}{c}{ IBR } & FRECUENCIA & PORCENTAJE \\
\hline Negativos & 52 & $64.35 \%$ \\
Positivos & 28 & $35.65 \%$ \\
Sospechosos & 0 & $0 \%$ \\
\hline \multicolumn{1}{c}{ TOTAL } & 80 & $100.0 \%$ \\
\hline
\end{tabular}


De acuedo con los resulltados obtenidos, se presume que la seropositividad expresada en los animales en estudio y la ausencia de manifestaciones clínicas evidentes, se pueden explicar por el hecho de que la IBR es una enfermedad primaria de fácil contagio y manifestaciones variadas (15), que tiene la facultad de establecer un estado de latencia, lo que permite al virus eludir el sistema inmunológico del organismo y mantenerse en el tiempo (16), provocando altas tasas de morbilidad, que en Colombia oscilan entre el 20-30\% (13). Las diferentes formas de la enfermedad podrían expresarse en la circunstancia de que haya reactivación viral, favorecida por factores estresantes que determinan un grado de inmunosupresión o inmuno-inhibición en los animales, con lo cual se interrumpiría el estado de latencia, dando lugar a la propagación del virus infeccioso y transmisión a los animales susceptibles (17).

En concordancia con los resultados obtenidos, se puede asegurar que aunque no se aprecia una manifestación clara de enfermedad al interior de los hatos lecheros del municipio de Toca Boyacá, la evidencia serológica demuestra actividad antigénica, lo que significa que en algún momento de su vida los animales han tenido contacto con el agente causal de la IBR, y por lo tanto se ha promovido la formación de anticuerpos contra el virus causante de esta entidad patológica.

Otro aspecto importante a considerar tiene que ver con el hecho de que, para el estudio en cuestión, las hembras se encuentran en una fase productiva exigente, lo cual significa para el estado general de las vacas, la exposición a variados factores capaces de desencadenar cierto grado de estrés y por lo tanto podrían ser determinantes en un estímulo a la inmunosupresión, evento que sería favorecedor de la entrada de agentes infecciosos causantes de enfermedad $(15,17)$, constituyéndose este factor en una posible causa de la seropositividad encontrada en el análisis de laboratorio.

Por otro lado, cuando se compara la seroprevalencia que se reporta con los hallazgos descritos en otros trabajos que se referencian en el territorio colombiano en los últimos 9 años, se han encontrado para diferentes regiones: prevalencia de $49 \%$ y $78 \%$ en Nariño y alto Putumayo respectivamente (18), 78.2\% en el Norte del Valle del Cauca (5), $35 \%$ en El Socorro-Santander(19) y $74.7 \%$ en Montería - Córdoba (3), queda claro, que los antecedentes y el nuevo aporte realizado por este trabajo, indican la amplia distribución de la enfermedad en el país, así como su alto grado de seropositividad.

Análisis de la variable edad. con el fin de facilitar la tabulación de datos para esta variable, el grupo de las 80 hembras muestreadas fue clasificado en diferentes categorías de acuerdo con la edad, obteniendo tres grupos homogéneos al interior y heterogéneos externamente, así: 1) Animales de 24 a 60 meses, que correspondieron a 39 vacas; 2) Animales de 72 a 108 meses, que correspondieron a 31 vacas; 3) Animales de 120 a 168 meses, que correspondieron a 10 vacas.

De esta manera, al hacer el análisis de la variable edad frente a la presentación de la IBR, se encontró en el grupo de 24 a 60 meses $17.9 \%$ de hembras positivas a la enfermedad, en animales de 72 a 108 se obtuvo un $60.7 \%$ de positividad y hembras de 120 a 168 meses tuvieron el $21.4 \%$ de positividad (Tabla 2 ).

Tabla 2. Resultado de seroprevalencia de la Rinotraqueitis Infecciosa Bovina, para cada una de las categorías del factor edad.

\begin{tabular}{ccc}
\hline \multirow{2}{*}{ EDAD (meses) } & \multicolumn{2}{c}{ IBR } \\
& POSITIVO & NEGATIVO \\
\hline 24- 60 & 5 & 34 \\
$\%$ seropositividad & 17.9 & 65.4 \\
$72-108$ & 17 & 14 \\
$\%$ seropositividad & 60.7 & 26.9 \\
120-168 & 6 & 4 \\
$\%$ seropositividad & 21.4 & 7.7 \\
\hline TOTAL & 28 & 52 \\
$\%$ seropositividad & 35.0 & 65.0 \\
\hline
\end{tabular}

Con base al análisis estadístico realizado para cada categoría de la variable edad, se observó una Odds Ratio (OR) de 1 en el primer grupo, es decir, que el hecho de que las hembras estén en un rango de edad de $24-60$ meses no se asocia con la probabilidad de presentación de la IBR.

En la categoría 2 y 3, la OR fue de 4.27 $(\mathrm{IC}=1.77-10.29)$ y 4.68 ( $\mathrm{IC}=1.7879-12.25)$, respectivamente, lo que sugiere que la edad podría ser posible factor de riesgo para aquellos animales que estuvieran por encima de los 60 meses, dada la posibilidad de infección por el virus de la IBR.

Para la prueba de tendencia lineal de la variable edad, el valor obtenido en el test exacto Fisher fue de 14.02, significativo para rechazar la hipótesis nula de no diferencia entre los grupos, 
con un valor $\mathrm{p}$ de 0.0002 , lo que indicó el grado de dependencia del factor edad con la posibilidad de presentación de la IBR, a pesar que las categorías en las que se dividió el grupo son heterogéneas.

Análisis de la variable problema reproductivo. En la correlación de seropositividad con el antecedente de problemas reproductivos, el grupo se dividió, de acuerdo con los datos obtenidos durante la encuesta, en dos conjuntos: hembras que en su historial reportaban alteraciones de tipo reproductivo y los animales sanos. Posteriormente se identificaron los animales positivos o negativos a IBR en cada uno de los grupos y se finalizó con un análisis individual de las variables aborto, repetición de celo y retención de placenta, frente a la presentación de la enfermedad.

Haciendo referencia al factor problemas reproductivos se encontró que el $31.3 \%$ de los animales presentaron algún tipo de alteración, sin embargo, de este grupo solo el $32.0 \%$ (8 vacas) fue positivo a IBR, además el OR obtenido $(0.82)$ y la prueba de Fisher (0.43) sugieren que no existe una asociación estadísticamente significativa para la variable problemas reproductivos frente a la presentación de la IBR, es decir, que a pesar de que los animales tengan alteraciones en su reproducción no significa que tengan la enfermedad, pero la enfermedad debe ser considerada a la hora de realizar un diagnostico diferencial pues la prevalencia obtenida no descarta la probabilidad de efectos infecciosos sobre los animales.

En concordancia con el análisis para la variable problemas reproductivos, se puede hacer un paralelo con los resultados de los estudios adelantados en la Universidad de Córdoba en 2006, que reportan prevalencia de IBR en vacas repetidoras y con antecedentes de aborto, el $74 \%$ de las primeras y el $70 \%$ de las segundas resultaron positivas, es así, como el coeficiente de asociación entre estas dos variables fue de solo el $4 \%$ el cual no resultó ser significativo, esto sugiere que la presencia de esta enfermedad es independiente y se tiene igual probabilidad de presentación para cualquiera de los estados reproductivos (3).

Análisis del factor aborto. Para esta variable, de las 80 hembras seleccionadas en el estudio el $2.5 \%$ ( 2 vacas) reportaron en su historial reproductivo un evento de aborto y el $97.5 \%$ (78 vacas) no.
Al realizar la valoración para la correlación del antecedente de aborto frente a la seropositividad para IBR, se encontró que las dos hembras que reportaron aborto, una fue positiva a IBR, lo que se traduce en $3.6 \%$, de frecuencia.

No obstante, al cruzar la variable antecedente de aborto con la seropositividad, se obtuvo un valor para la Odds Ratio (OR) de 1.88 (IC $=0.116$ 31.40), lo que podría significar una relación positiva de la infección con los abortos, lo que convertiría a la IBR en un posible factor de riesgo para la ocurrencia del aborto. En la prueba del test exacto de Fisher se alcanzó un resultado de 0.5803 , lo cual indica que no se evidencia una asociación estadísticamente significativa.

Por otro lado, al evaluar cada uno de los problemas presentados en los hatos lecheros muestreados se determinó que el aborto es un factor de riesgo en la presentación de IBR, pero en el estudio su asociación estadística no fue significativa, resultado que concuerda con lo reportado por Magaña Urbina et al (20), en el estudio de Rinotraqueitis infecciosa bovina en hatos lecheros de la región Cotzio-Téjaro, quienes reportaron que no se encuentra asociación entre la presencia de anticuerpos a IBR y antecedentes de abortos o la presencia de vulvovaginitis.

Con base en lo anterior se puede afirmar que existen otros elementos ajenos a la enfermedad que podrían inducir la interrupción de la gestación, dentro de los que se podrían incluir agentes infecciosos como la diarrea viral bovina (DVB)(21), Virus bovino parainfluenza 3 (BPI3), virus sincitial respiratorio bovino(22), Campilobacter, Trichomona, Leptospira, sumados a factores nutricionales y de manejo $(18,23)$.

Análisis de factor repetición de celo. Para esta variable durante la encuesta no se especifica si la repetición de celo se debe a reabsorción embrionaria, vaca repetidora o aumento en el índice de numero de servicios por concepción, sin embargo, se obtuvo como resultado, que de las 80 hembras muestreadas el $25 \%$ correspondiente a 20 vacas, tuvieron repetición de celo y el 75\%, 60 vacas en total, no presentaron esta alteración.

Del mismo modo al realizar la determinación respectiva para los 20 animales que presentaron repetición de celo, se halló una seropositividad del $25 \%$ para IBR, porcentaje representado en 7 animales de los 28 que fueron seropositivos a la enfermedad. 
Frente al factor repetición de celo/positividad a IBR, se tiene un OR de 1.00 (0.3461-2.88) y un valor para el test exacto de Fisher de 0.601 , quedando descartada de esta manera la probable asociación estadística entre el la reactividad a IBR y el factor repetición de celo.

Análisis factor retención de placenta. En el análisis de esta variable, se encontró que 3 animales, o sea $3.8 \%$ del total de la muestra analizada, presentaron retención de placenta, y 77 hembras que equivale al $96.3 \%$ no registraron el antecedente.

De igual forma al evaluar si alguna de las hembras con retención de placenta había presentado seropositividad a IBR se determinó que ninguna tenía la enfermedad. En este sentido encontramos para retención de placenta un $\mathrm{OR}=0.0$ y Test Exacto de Fisher, de 0.27, demostrando así, que no hay asociación epidemiológica y el resultado no es estadísticamente significativo.

Para finalizar y teniendo en cuenta el análisis realizado para la variable problemas reproductivos, se concluye que epidemiológicamente no hay relación ni tampoco dependencia de estas variables y la manifestación de la enfermedad, demostrando que el hecho de presentar problemas reproductivos no es un indicador de que el animal sea positivo al contacto previo con el agente causal de la IBR. Información relacionada con lo reportado en el estudio de Magaña Urbina et al (20), quienes no encontraron asociación entre la presencia de anticuerpos a IBR y el intervalo entre partos y número de días abiertos.

Análisis de la variable partos. De otra parte, para el factor partos / vaca no hubo un alto índice de paridad (en promedio se tiene 3 partos por vaca), aunque se debe tomar como referencia la edad de cada una de las hembras. Para efectos de organización el grupo se dividió en tres categorías, así: 1). Animales que han tenido entre 1 a 2 partos. 2). Animales que han tenido entre 3 a 4 partos. 3). Animales que han tenido entre 5 a 9 partos.

En concordancia con la subdivisión, se obtuvo que en el grupo uno se encuentra el $43.8 \%$ de los animales de estudio, es decir 35 hembras, y para los grupos dos y tres se tiene el 36.3\% (29 hembras) y $20 \%$ ( 16 hembras) respectivamente.

En lo referente a la cantidad de partos que han tenido las vacas y la presentación de la IBR, se obtiene que para animales del grupo uno (Tabla 3) hubo una seroprevalencia del $17.9 \%$,
Tabla 3. Resultado de presentación de IBR para el factor paridad.

\begin{tabular}{|c|c|c|c|}
\hline & \multirow{2}{*}{ PARTOS } & \multicolumn{2}{|c|}{ IBR } \\
\hline & & POSITIVO & NEGATIVO \\
\hline$\%$ & $\begin{array}{c}1 \text { a } 2 \\
\text { seropositividad }\end{array}$ & $\begin{array}{c}5 \\
17.9\end{array}$ & $\begin{array}{c}30 \\
57.7\end{array}$ \\
\hline$\%$ & $\begin{array}{l}3 \text { a } 4 \\
\text { seropositividad }\end{array}$ & $\begin{array}{c}15 \\
53.6\end{array}$ & $\begin{array}{c}14 \\
26.9\end{array}$ \\
\hline$\%$ & $\begin{array}{c}5 \text { a } 9 \\
\text { seropositividad }\end{array}$ & $\begin{array}{c}8 \\
28.6\end{array}$ & $\begin{array}{c}8 \\
15.4\end{array}$ \\
\hline$\%$ & $\begin{array}{l}\text { TOTAL } \\
\text { seropositividad }\end{array}$ & $\begin{array}{c}28 \\
35.0\end{array}$ & $\begin{array}{c}52 \\
65.0\end{array}$ \\
\hline
\end{tabular}

en el grupo dos se encuentra positividad del $53.6 \%$ y para el grupo tres se tiene un $28.6 \%$ de seropositividad.

Al evaluar el factor paridad, se toma para los tres niveles el Odds Ratio y arroja un resultado de 1 para la categoría uno y se considera como no asociada al evento de presentación de la IBR, para la categoría dos y tres se obtiene un valor de OR $=3.6207$ ( $\mathrm{IC}=1.4952-8.7676)$ y $3,50(\mathrm{IC}=1.3564-9.0315)$ respectivamente, con lo cual se concluye que, en concordancia con lo hallado para la edad, el número de partos se asocia significativamente con la probabilidad de contagio con el microorganismo responsable de la IBR, lo que hace de la paridad un posible factor de riesgo para la presentación de la infección.

Confirmando lo expuesto, al correr el valor del test exacto de Fisher, se obtuvo un resultado de 8.6951, el cual se consideró significativo, con un valor $p$ de 0.0032 , lo que indica el grado de dependencia de la variable paridad con la presentación de la IBR.

Con base en lo anterior, al analizar el factor paridad, y teniendo en cuenta que los grupos en los que se dividió el total de las hembras muestreadas fueron heterogéneos, se encontró una relación directa entre la presentación de la IBR y la variable, evento que se puede explicar por el hecho de que el parto es un factor natural que estimula la inmunosupresión y por lo tanto la reactivación viral (24). Además, la edad avanzada y el contacto reproductivo con toros infectados o inseminación artificial con semen contaminado son factores que influyen en la aparición de la ya nombrada patología.

Aunque estadísticamente para el factor paridad la dependencia que existe entre el número de partos por vaca y la presentación de la IBR se consideró significativa, se debe tener en cuenta que por no ser los grupos a estudio homogéneos, 
se debe tomar con cautela la inferencia de que a mayor cantidad de partos existe un incremento en las posibilidades de que las vacas sean seropositivas.

Es importante anotar, que el estudio refleja el contacto que han tenido los animales pertenecientes a los hatos lecheros del municipio de Toca-Boyacá, con el agente causal de la IBR, a pesar de que no se han referenciado evidencias clínicas de la presencia de esta enfermedad, es de vital importancia identificar todas aquellas variables que podrían estar facilitando la diseminación de la enfermedad en la zona, para que con el apoyo de datos válidos y confiables, fruto de tamizajes, que reflejen el estado sanitario de la región, se puedan establecer medidas profilácticas, dentro de las cuales se encuentra la vacunación, y de esta forma ayudar a controlar la difusión.

\section{DISCUSIóN}

Los resultados del estudio en Toca - Boyacá contrastan con las cifras obtenidas en otra investigación, en la que un grupo de animales con edades entre los 36 y 48 meses se presentó un $36.1 \%$ de hembras positivas a IBR, mientras que entre 60 y 72 meses el resultado fue del $46.3 \%$ (3), también con los guarismos reportados en el estudio de San Gil para vacas mayores de 36 meses las cuales tuvieron 56\% de prevalencia de seropositividad (19).

Es evidente en los diversos estudios adelantados que la seropositividad para la IBR en animales mayores a 24 meses es alta, sin embargo, la heterogeneidad de los grupos en este estudio limita la formulación de un concepto claro respecto a la presentación de IBR en relación con la edad de los animales, por lo tanto, no es posible afirmar que a medida que aumenta la edad aumenta la probabilidad de presentar IBR, contrario a lo enunciado que en cuanto a la edad, hay mayor sepositividad en los adultos, lo cual tiene relación con el hecho de que estos animales han tenido mayor posibilidad de estar en contacto con el virus (19).

Por otro lado se puede decir que en todos los grupos de edad evaluados se hallaron animales positivos, lo cual implica la existencia de un factor común a partir de los 24 meses que predispone el contagio de la enfermedad y puede ser el hecho, que en esta época las vacas inician su etapa reproductiva, por lo tanto, son hembras que deben ser inseminadas artificialmente o montadas directamente por el toro de reproducción, eventos catalogados por la literatura como factores transmisores de la enfermedad $(5,25)$.

La seroprevalencia hallada para la IBR, mediante la utilización de la prueba de ELISA, en el municipio de Toca - Boyacá, fue, con la respectiva corrección para una sensibilidad de $96 \%$ y especificidad de $97 \%$, del $35.65 \%$ y un intervalo de confianza (95\%) de 24.7 a $46.5 \%$, lo que significa que de los 80 bovinos muestreados 28 vacas registraron títulos que sugieren evidencia de la enfermedad, dato que demuestra que estos animales han sido expuestos, por lo menos una vez al contacto infeccioso con el agente causal de la enfermedad, pues las fincas muestreadas no tienen historia de vacunación contra IBR, por lo tanto, se asume que existen factores que favorecieron la entrada y están ayudando a distribuir el virus dentro de la población.

Los hallazgos serológicos para la IBR, en el municipio de Toca-Boyacá, constituyen un primer aporte mediante estudio de investigación rigurosos y sistemático, que demuestra la presencia de la enfermedad en la zona y a la vez, indica que esta afección puede ser uno de los posibles factores de riesgo que afecta la rentabilidad económica de la producción lechera.

Los altos registros de seropositividad que se obtuvieron en el municipio de Toca-Boyacá, se constituyen en una llamada de alerta, pues demuestran de manera fehaciente la actividad viral extendida que presenta la IBR en la zona, con lo cual se podría considerar a esta enfermedad como endémica en esta área, ya que se encuentran muchos animales con valores de seropositividad homogéneos pero sin evidencia de manifestaciones clínicas o impacto importante en los parámetros productivos y reproductivos de las vacas.

Los datos obtenidos en el estudio para el factor edad mostraron que animales de 24 - 60 meses, presentaron el $17.9 \%$ de hembras positivas a IBR, para animales de 72 - 108 meses se encontró un $60.9 \%$ de positividad para IBR y por último los de 120 - 168 meses, tuvieron el $21.4 \%$ de animales positivos, por lo tanto no se concreta evidencia que demuestre la relación entre el aumento de la edad, con la posibilidad de tener valores de seropositividad para IBR, sin embargo, queda claro que en el grupo dos, podrían estar presentes factores aún no precisados o delimitados diáfanamente que influyen en la activación de respuesta inmune a la IBR. 
De acuerdo con la relación existente entre número de partos y la presentación de la IBR, para los animales que reportan en su historial 1 - 2 partos se obtuvo una seroprevalencia del $17.9 \%$, en animales que tuvieron $3-4$ partos se encuentra positividad del $53.6 \%$ y para aquellas con 5 - 9 partos se tiene un $28.6 \%$ de seropositividad, demostrando que las vacas que alcanzaron mayor número de partos tienen mas probabilidad de presentar títulos elevados de respuesta inmunológica a la enfermedad.

La relación existente entre los problemas reproductivos y la presentación de la IBR, en hatos lecheros del municipio de Toca - Boyacá, es independiente, teniendo igual probabilidad de presentación para cualquiera de los estados reproductivos, lo que muestra ausencia de asociación entre la variable y la enfermedad, por lo tanto, el hecho de existir fallas en la reproducción no es un indicador que pueda atribuirse a la presencia de la enfermedad en los animales.
Existen estudios que han dado a conocer evidencia de seropositividad para la IBR, en diversas áreas y sistemas productivos bovinos del territorio nacional, sin embargo, la información que se tiene es insuficiente para establecer el estatus sanitario de esta entidad en las diferentes regiones de Colombia, por lo tanto, la situación epidemiológica no es clara y dificulta la elaboración de estrategias especificas de prevención y control de la enfermedad.

En conclusión, el presente trabajo constituye el primer reporte de análisis de esta enfermedad en el municipio de Toca-Boyacá, que demuestra la presencia de la enfermedad en la zona. Simultáneamente, se plantea que esta afección pueda ser uno de los posibles factores de riesgo que afecta la rentabilidad económica de las producciones lecheras.

\section{REFERENCIAS}

1. Radostits OM, Littlejohns IR. New concepts in the pathogenesis, diagnosis and control of diseases caused by the bovine viral diarrhea virus. Can Vet J 1988; 29(6):513.

2. Armstrong JA, Pereira HG, Andrewes $\mathrm{CH}$. Observations on the virus of infectious bovine rhinotracheitis, and its affinity with the Herpesvirus group. Virology 1961; $14: 276-85$.

3. Betancur C, Marco González T, Reza L. Seroepidemiología de la Rinotraqueitis Infecciosa bovina en el municipio de Montería, Colombia. Rev MVZ Cordoba 2006; 11(2):830-36.

4. Dias LE, Maisonnave J, Guarino $H$, Paullier C, Perdomo E, Figares A, et al. Rinotraqueitis Infecciosa Bovina (IBR), descripción de un cuadro clínico en terneros de tambo. Montevideo: Anais III Congr. Nac. Veterinaria; 1982.

5. Diaz FA, Lozano A. Reactividad serologica y aspectos epidemiologicos relacionados a la rinotraqueitis infecciosa bovina (ibr) mediante la prueba de seroneutralizacion viral en toros reproductores. REDVET 2002; $\operatorname{III}(15)$.
6. Hochstein-Mintzel V, Riedemann S, Reinhardt G, Niedda $M$. Rinotraqueitis infecciosa bovina. Relacion entre titulos de anticuerpos y des indices reproductivos en un plantel lechero. J Vet Med B 1986; 33(9):697-703.

7. Kahrs RF. Infectious bovine rhinotracheitis: a review and update. J Am Vet Med Assoc 1977; 171(10):1055.

8. Moraga B L, Ruidiaz G E, Zurita A L, Celedon MO, Berrios E P. Reproduccion experimental de rinotraqueitis infecciosa bovina. 1: Inoculacion de dos cepas del virus herpes bovino tipo 1 aisladas en Chile. Avances en Ciencias Veterinarias 1987; 2(1):26-32.

9. Griffiths IB, Gallego MI, Villamil LC. Factores de infertilidad y pérdidas económicas en ganado de leche en Colombia. Bogotá D.E: Instituto Colombiano Agropecuario; 1982.

10. Góngora A, Villamil LC, Vera V, Ramírez G, Parra J. Diagnóstico de las principales enfermedades reproductivas en toros de la Sabana de Bogotá. Énfasis en RIB. Rev Med Vet Zoot 1995; 43:37-41. 
11. Información municipal para la Toma de decisiones. Colombia, Toca: Departamento Nacional de Planeación, Federación Colombiana de Municipios; 2011 [accesado 2011 25-09]; URL Disponible en: www. boyaca.gov.co/index.php?idcategoria $=330$ 3\&download $=Y$

12. Graham DA, Mawhinney KA, McShane J, Connor TJ, Adair BM, Merza $M$. Standardization of enzyme-linked immunosorbent assays (ELISAs) for quantitative estimation of antibodies specific for infectious bovine rhinotracheitis virus, respiratory syncytial virus, parainfluenza-3 virus, and bovine viral diarrhea virus. J Vet Diagn Invest 1997; 9(1):24.

13. Navarrete J, Vera V, Ramírez G, Villamil LC. Evaluación de la prueba ELISA usando una cepa de campo como antígeno, para detectar anticuerpos contra el virus de la Rinotraqueitis Bovina Infecciosa. NOVA 2004; 2(2):1-108.

14. Van Oirschot JT, Kaashoek MJ, MarisVeldhuis MA, Weerdmeester $K$, Rijsewijk FAM. An enzyme-linked immunosorbent assay to detect antibodies against glycoprotein $\mathrm{gE}$ of bovine herpesvirus 1 allows differentiation between infected and vaccinated cattle. J Virol Methods 1997; $67(1): 23-34$.

15. Straub OC. Advances in BHV1 (IBR) research. Dtsch Tierarztl Wochenschr $2001 ; 108(10): 419$.

16. Ackermann M, Belak S, Bitsch V, Edwards S, Moussa A, Rockborn G, et al. Round table on infectious bovine rhinotracheitis/ infectious pustular vulvovaginitis virus infection diagnosis and control. Vet Microbiol 1990; 23(1-4):361-3.

17. Muylkens B, Thiry J, Kirten P, Schynts F, Thiry E. Bovine herpesvirus 1 infection and infectious bovine rhinotracheitis. Vet Res 2007; 38:181-209.

18. González Cardona HG, Burbano P. Principales agentes infectocontagiosos del aborto e infertilidad en el ganado lechero de Nariño y Alto Putumayo. San Juan de Pasto: Corpoica-Pronatta; 1999.
19. Zambrano-Valdivieso EO. Determinacion de la seroprovalencia de Rinotraqueitis Infecciosa Bovina IBR en el municipio del Socorro Santander. Bucaramanga: Unversidad Cooperativa de Colombia; 2005.

20. Magaña-Urbina A, Solorio Rivera JL, Segura-Correa JC. Rinotraqueitis infecciosa bovina en hatos lecheros de la región Cotzio-Téjaro, Michoacán, México. Téc Pecu Méx 2005; 43(1):27-37.

21. Rondón L. Diarrea viral bovina: patogénesis e inmunopatología. Rev MVZ Córdoba 2006; 11(1):694-704.

22. Bagnis G. Infecciones virales respiratorias producidas por el virus sincitial respiratorio bovino (VSRB) y el virus Parainfluenza 3 bovino (BPI3). Rio Cuarto, Cordoba, Argentina: El Sitio de la Producción Animal; 2006 [accesado 2011 2609]; URL Disponible en: http://www. produccion-animal.com.ar/sanidad_ intoxicaciones_metabolicos/infecciosas/ bovinos_en_general/13-infecciones_ virales_respiratorias_por\%20virus.pdf

23. González M, Ríos R, Mattar $S$. Prevalencia de bacterias asociadas a la infertilidad infecciosa en bovinos de Montería, Colombia. Rev MVZ Córdoba 2007; 12(2):1028-35.

24. Perez $S$, Inman $M$, Doster $A$, Jones $C$. Latency-related gene encoded by bovine herpesvirus 1 promotes virus growth and reactivation from latency in tonsils of infected calves. J Clin Microbiol 2005; 43(1):393-401.

25. Parsonson IM, Snowdon WA. The effect of natural and artificial breeding using bulls infected with, or semen contaminated with, infectious bovine rhinotracheitis virus. Aust Vet J 1975; 51(8):365-9. 